\title{
A construção de um banco ótico para a difração da luz em fendas únicas e múltiplas de fácil acesso e a utilização do tracker como ferramenta de estudo
}

\author{
Construction of an Optical Bank for Diffraction of Light \\ in Single and Multiple Slits for Easy Access and use of \\ the software Tracker as a Study Tool
}

DOI https://doi.org/10.36411/AEF.1.2.7

Katherine Maslova

ORCID: https://orcid.org/0000-0001-9276-1218

Instituto Federal de Educação, Ciência e Tecnologia do Rio de Janeiro, katherinedefante@gmail.com

Carlos Pérez

ORCID: https://orcid.org/0000-0003-3564-8109

Instituto Federal de Educação, Ciência e Tecnologia do Rio de Janeiro, carlos.perez@ifrj@edu.br

Recibido: 10 de octubre de 2019

Aceptado: 20 de diciembre de 2019

\section{Resumo}

O alto custo de um aparato experimental faz com que as escolas não destinem seus investimentos à construção de laboratórios, causando defasagem no ensino experimental de Física. Como forma de diminuir a desigualdade entre as escolas que possuem alto investimento e as que não possuem e levar a Física experimental aos alunos, este trabalho apresenta a construção de fácil acesso de um banco ótico para a difração da luz em fendas única e múltiplas. A construção desse experimento permite a observação e comprovação da natureza das ondas de luz e, com o auxílio do software livre Tracker, que é usado como ferramenta metodológica, torna-se possível a determinação das relações entre comprimento de onda e tamanho das fendas. Como os valores tratados para comprimento de ondas e distâncias entre as franjas de difração são pequenos, se tornam difíceis de serem determinados a olho nu, porém, utilizando ferramentas computacionais, esse problema é solucionado.

Palavras - chave: construção, experimento, difração, Tracker.

\begin{abstract}
The high cost of an experimental apparatus means that schools do not allocate their investments to the construction of laboratories, causing an inequality in the experimental teaching of physics. As a way to reduce the inequality between high-investment and low-investment schools and to bring experimental physics to students, this paper presents the easy access construction of an optical bench for light diffraction in single and multiple slits. The construction of this experiment allows the observation and verification of the nature of light and, with the help of free software Tracker, which is used as a methodological tool, it is possible to determine relationship between the wavelength and the slit's size. Since the values treated for wavelengths and distances between the diffraction fringes are small, they become difficult to be determined for the naked eye, but using computational tools, this problem is solved.
\end{abstract}

Key-Words: construction, experiment, diffraction, Tracker. 


\section{Introdução}

Como explicitado por Abib e Araújo, a formação da cidadania das pessoas tem como fator constituinte o entendimento da natureza, incluindo a da Física. O ensino de Física somente de maneira teórica não consegue abranger de modo completo essa formação para as pessoas, sendo necessário aliar a teoria à prática. Além de ter a física teórica com essa importância de fator constituinte, "o uso de atividades experimentais como estratégia de ensino de Física tem sido apontado por professores e alunos como uma das maneiras mais frutíferas de se minimizar as dificuldades de se aprender e de se ensinar Física de modo significativo e consistente" (ABIB, ARAÚJO).

Embora seja sabida a necessidade da física experimental, a realidade de possuir aparatos para desenvolver a mesma é distante dos alunos de escolas públicas brasileiras. O Censo Escolar realizado pelo INEP em 2018 mostrou que 60,6\% das escolas de educação básica brasileira são municipais e dentre toda essa porcentagem, apenas $28,8 \%$ dessas escolas possuem laboratório de ciências, valendo ressaltar que a Física não necessariamente precisa estar incluída. Como a maior parte das escolas não possuem acesso a experimentos de física para os alunos, há uma segregação grande entre os alunos que estudam em escolas municipais e os alunos que estudam nas escolas particulares, que são o segundo maior número de escolas do Brasil (22,3\%) e 44,1\% delas possuem laboratórios. Ainda que menos da metade delas possuam laboratórios, a discrepância entre as escolas possui um valor alto.

Como forma de contornar esse problema e levar a física experimental a todos de forma igualitária, este estudo tem como objetivo mostrar que é possível fazer ciência de forma barata e com a participação dos próprios alunos, que podem fazer parte da montagem experimental com o professor. Será utilizada uma experimentação na qual o estudante exerce papel fundamental em sua montagem tornando assim o processo de desenvolvimento do conhecimento algo mais acessível a este (CARVALHO, 2013).

Alguns conteúdos de física, como a difração da luz, também podem parecer difíceis de experimentar ou de analisar sem os equipamentos e tecnologias necessárias. Para desviar dessa concepção alternativa dos alunos, será utilizado o software Tracker como instrumento de ensino e análise de dados.

Os fenômenos ondulatórios da difração e interferência acontecem com qualquer tipo de onda, seja mecânica ou eletromagnética. No caso da luz, a difração ocorre quando ela passa por um obstáculo que tenha tamanho de igual ordem de grandeza que o seu comprimento de onda. Já a interferência luminosa, acontece quando mais de uma onda se encontram num mesmo local ao mesmo tempo, somando-se nesse ponto.Na figura 1podemos observar os fenômenos de difração e interferência. 

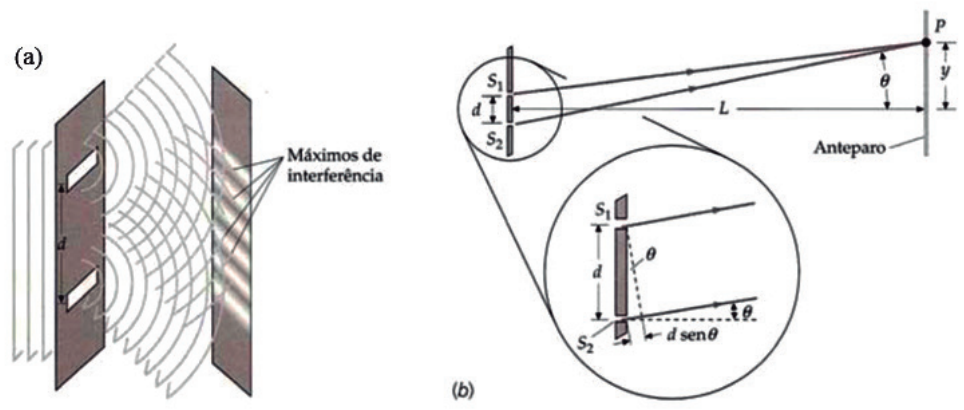

Figura 1: Imagem ilustrativa dos fenômenos de difração e interferência

Acerca da figura 1 (retirado de Tipler e Mosca, 2006), podemos ver no item (a) a observação do fenômeno de interferência da luz em fendas duplas. Já no item (b), temos a relação geométrica entre a distância y medida ao longo do anteparo a L e $\theta$. O fato da distância do anteparo ser muito maior que a distância de separação entre as fendas faz com que os raios cheguem aproximadamente paralelos, assim, a diferença de caminho ótico entre os raios é d.sen( $(\theta)$, fazendo que tenhamos a relação:

$$
\lambda=\mathbf{n} \cdot \mathbf{d} \cdot \operatorname{sen} \theta(1)
$$

Onde: “ $\lambda$ ” é o comprimento de onda do laser, "n" é a ordem do máximo de difração, "d" é a distância entre as fendas (no caso da fenda dupla) e o ângulo a ser utilizado pode ser aproximado para $\theta \cong \operatorname{sen}(\theta)=\frac{x}{L}$, considerando " $\mathrm{x}$ " a posição medida pelo software Tracker e " $L$ " a distância entre a fenda e o anteparo.

O estudo dos fenômenos ondulatórios em sala de aula é comumente feito através da experimentação, como feito por SOUZA e DARROZ, porém, sem o uso de softwares computacionais que possam facilitar a obtenção de valores mais precisos, que é a ideia principal deste trabalho.

\section{Material utilizado}

- Duas lâminas de barbear;

- Pedaço de papel-cartão de tamanho $23,5 \mathrm{~cm}$ X $15 \mathrm{~cm}$;

- Pedaço de madeira de tamanho 23,5 cm X $15 \mathrm{~cm}$;

- Pedaço de madeira de tamanho 10,7 cm X 10,7 cm;

- Fita isolante ou fita autocolante;

- Laser;

- Velcro;

- Fio de diâmetro 0,03 cm;

- Dois trilhos de cortina de 1,30 m;

- Cola quente;

- Fita métrica;

- Folha de papel milimetrado;

- Arco de serra;

- Seisímãs decorativos. 
É importante ressaltar que o tamanho e origem das peças possuem liberdade de alteração dependendo da grandeza de preferência do experimento, assim como é válido a substituição das mesmas.

\section{Metodologia de construção do experimento}

A construção do aparato experimental será dividida em duas etapas. A primeira etapa terá como objetivo a instrução para a montagem das fendas única e dupla, enquanto a segunda parte será voltada para a organização do banco ótico e fechamento da construção.

\section{Primeira etapa:}

- Iniciando a construção da fenda única, uma lâmina de barbear deve ser partida ao meio;

- Cole um lado da lâmina partida em cima do papel cartão;

- Um pedaço de papel qualquer dobrado ao meio terá sua espessura utilizada como abertura da fenda. Posicione a dobra do papel exatamente na extremidade lateral da lâmina cortada, apenas segurando;

- Utilize a outra mão para posicionar o outro pedaço da lâmina no outro lado do papel dobrado e cole-a;

- Retire o papel;

- O espaço entre as extremidades das lâminas será a espessura do papel dobrado utilizado;

- Com o auxílio de um estilete, corte o espaço entre as lâminas para permitir a passagem de luz.

Após a montagem,a fenda única ficará com a aparência observada na figura 2.

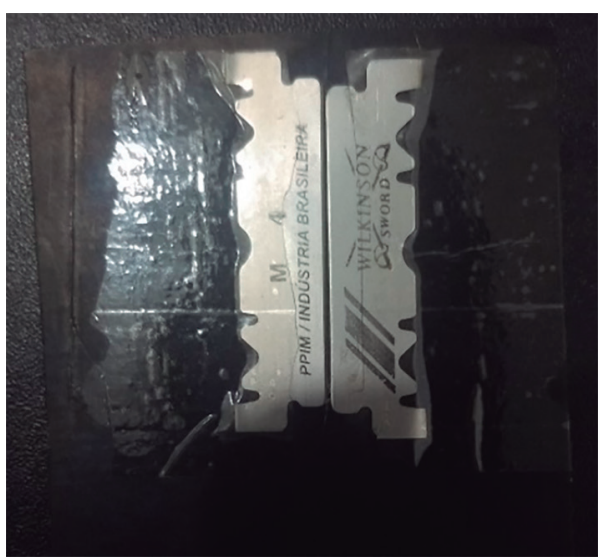

Figura 2: fenda única após a montagem

- Para a montagem da fenda dupla, precisaremos utilizar o pedaço de madeira de tamanho 23,5 cm X $15 \mathrm{~cm}$ e da outra lâmina de barbear e do pedaço de fio de diâmetro $0,03 \mathrm{~cm}$;

- É necessário fazer um furo no pedaço de madeira;

- Quebre a outra lâmina de barbear ao meio; 
- Cole um lado da lâmina partida de forma que sua extremidade apareça no furo e o outro pedaço de lâmina fique no outro lado do furo, utilize fita isolante ou fita autocolante;

- No espaço entre as extremidades das lâminas, o pedaço de fio deve ser colado.

- A fenda dupla ficará com a aparência que pode ser vista na figura 3. Na figura 4 é possível visualizar a imagem do furo com maior aproximação

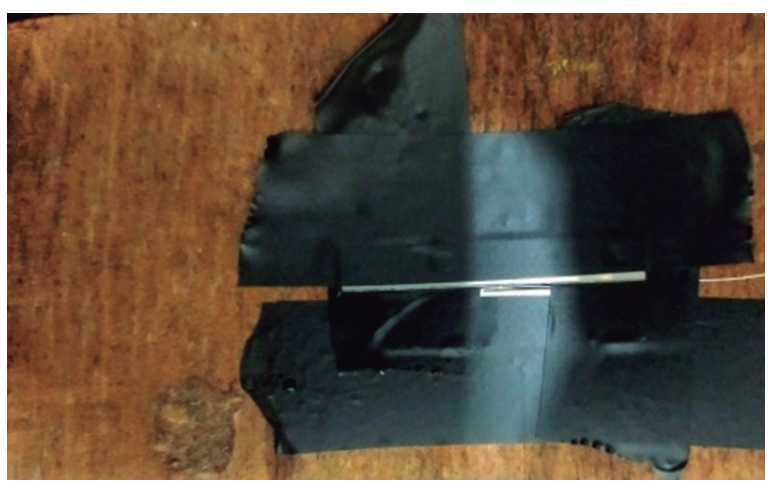

Figura 3: fenda dupla após a montagem

Repare na foto aproximada do furo:

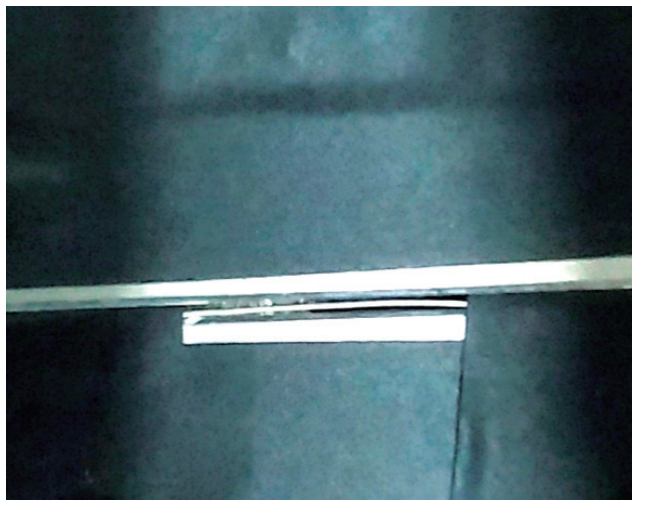

Figura 4: imagem aproximada da fenda dupla

Utilizando o outro pedaço de madeira de tamanho $32 \mathrm{~cm}$ X $32 \mathrm{~cm}$, cole um pedaço de papel milimetrado de mesmo tamanho por cima. Caso ache necessário, passe fita autocolante sobre o papel para protegê-lo.

É válido ressaltar que para obter uma boa qualidade da difração da imagem da fenda dupla, é importante que o fio esteja bem esticado e o espaço entre as fendas esteja bem fino.Embora não seja necessário para a montagem da fenda, utilize uma lupa ou microscópio a fim de facilitar a visualização, como exemplificado na figura 5. 


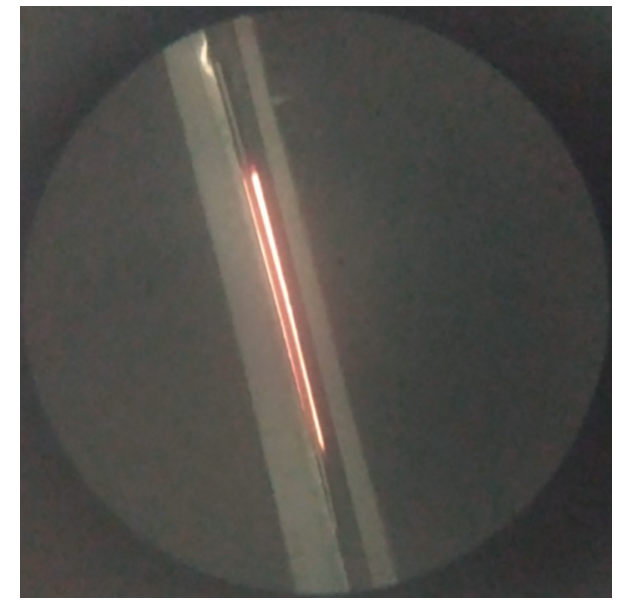

Figura 5: imagem da fenda dupla vista de um microscópio

Observe na figura 6 como os materiais ficarão após o fim da primeira parte da montagem.

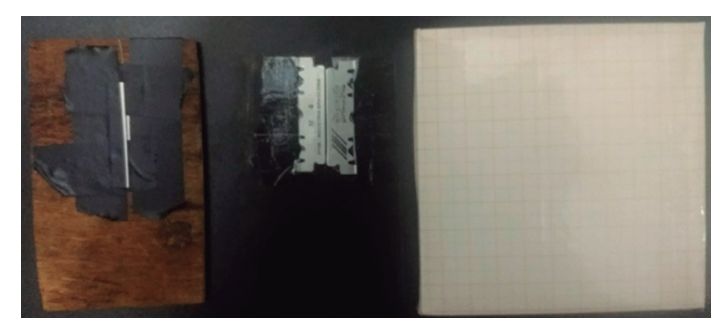

Figura 6: imagem das fendas e do anteparo

\section{Segunda parte:}

- Com a ajuda de um arco de serra, corte um dos trilhos de cortina em 3 pedaços iguais;

- Com o auxílio dos seis ímãs decorativos, cole-os pela metade na parte de baixo dos pedaços cortados, eles auxiliarão esses pedaços a ficarem em pé em cima do trilho maior;

- Em uma das partes de trilho cortadas ficará colada na parte superior o pedaço de madeira coberto pelo papel milimetrado, utilize cola quente;

- $\mathrm{Na}$ outra parte de trilho cortada ficarão as fendas, cole um lado do velcro no pedaço de trilho e o outro pedaço na parte de trás da fenda, assim, elas poderão ser trocadas ;

- Na terceira parte de trilho cortada, ficará apoiado na parte superior o laser. Com o auxílio de um pedaço de papel cartão retangular, apoie o laser sobre o pedaço do trilho;

- Cole a fita métrica em cima do trilho maior;

- Para que o laser fique ligado enquanto o experimento ocorre, passe uma fita auto colante ou fita isolante de modo bem apertado ao redor do botão.

- Com o fim da montagem, o experimento ficará como visto nas figuras 7, 8 e 9. 


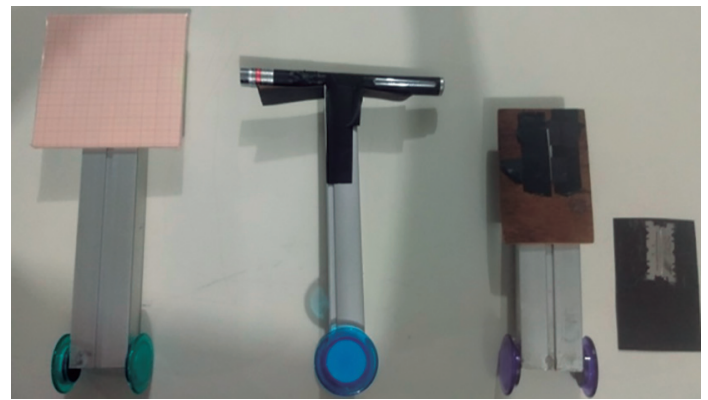

Figura 7: imagem dos trilhos cortados com suas peças montadas

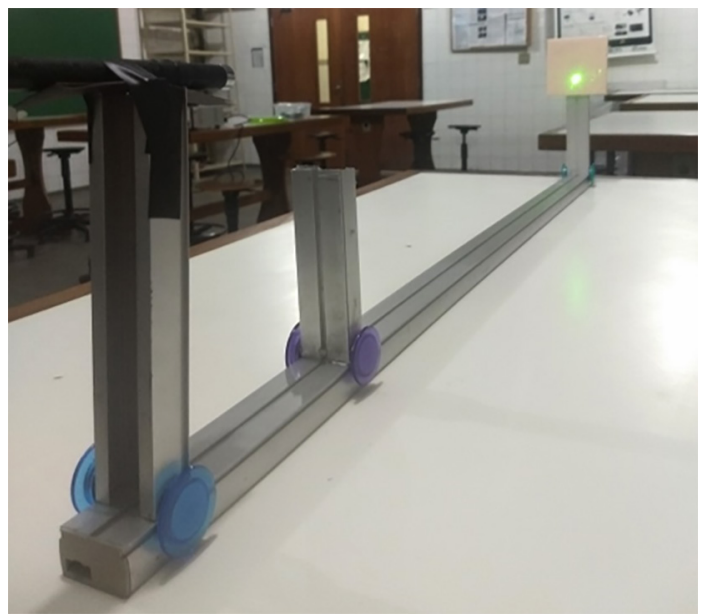

Figura 8: imagem do trilho montado em perspectiva sem o uso das fendas

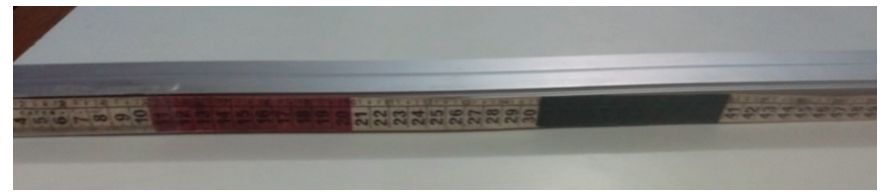

Figura 9: imagem da lateral do trilho com a fita métrica para a medição de distância

\section{Metodologia de ensino}

Nessa etapa, é essencial que os alunos já possuam algum conhecimento prévio da teoria para que a prática seja aplicada. Neste experimento, as distâncias entre o laser, a fenda e o anteparo poderão ser alteradas, o que permite uma maior coleta de resultados.

Os alunos devem ser instruídos a ligar o laser e colocar os pedaços de trilho cortados nas distâncias que podem ser indicadas pelo professor ou decididas entre eles mesmos. Quando a luz do laser difratar, passando pela fenda, uma imagem ficará projetada no anteparo, é dessa imagem que o aluno precisará tirar uma foto para analisar, como exemplo, a figura 10. É importante lembrar ao aluno de tirar uma foto paralela à imagem projetada no anteparo.

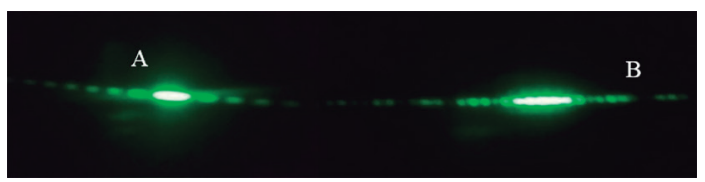

Figura 10: imagens obtidas por câmera de celular para as fendas única (A) e dupla (B) 
Com a fotografia feita pelos alunos, eles poderão utilizar o software Tracker para analisar e coletar dados. Para aqueles que não possuem facilidade com o software, a seguir serão apresentadas instruções para o uso do aplicativo.

\section{Utilizando o Tracker:}

- Abra o software e no menu arquivo, abra a foto tirada;

- Clique no ícone chamado "Fita métrica com transferidor" > Novo > Fita de calibração;

- Segurando a tecla "Shift" do teclado, clique na extremidade de um tamanho que você conheça na imagem, (no caso, pode ser utilizado o papel milimetrado) segure "Shift" novamente e clique na outra extremidade. Irá surgir uma caixa com um valor de tamanho dentro, edite para o valor de tamanho do item que você marcou (em metros). Após a calibração de tamanho, a fita pode ser movida para outro lugar da imagem, caso esteja na frente da difração.

- Clique em "Mostrar eixos de coordenadas" e arraste até o centro da imagem projetada, em cima da franja localizada no meio. Gire um pouco o eixo, caso precise.

- Vá até o menu Trajetórias > Novo > Perfil da linha

- Segure "Shift" e clique na primeira franja de luz, depois arraste a extremidade do quadro até a última franja;

- Clique em "Perfil A" no quadrado que apareceu > Orientação > Paralelo ao eixo $\mathrm{x}$. Caso precise enquadrar a fita melhor na imagem das franjas, mova a fita.

- Caso precise engrossar a linha de leitura, altere o valor na caixa "Expandir";

- O gráfico já aparece automaticamente ao lado, ele faz a leitura por intensidade luminosa e posição, a tela vista no computador deve ser semelhante à figura 11;

- Clicando sobre o gráfico com o botão direito, é possível clicar em analisar o obter mais dados.

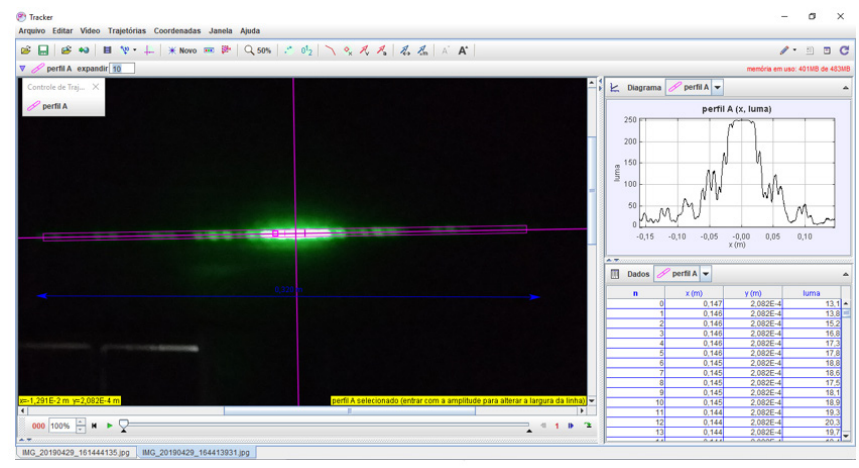

\section{Análise de dados e resultados}

Com o gráfico do Tracker (Figuras 12 e 13) é possível entender a importância da utilização do software. Os valores de distância entre as franjas de luz não poderiam ser obtidas de forma tão satisfatória a olho nu, o que é facilmente 

tiplas de fácil acesso e a utilização do tracker como ferramenta de estudo

contornado com o uso do programa. Além dos alunos conseguirem fazerem diferentes coletas de dados, alterando do modo que preferirem as distâncias, eles conseguem experimentar um tema da física que pode parecer distante com a ausência de um experimento e com a falta de um instrumento que auxilie a coleta de valores que seriam improváveis sem um preparo adequado.
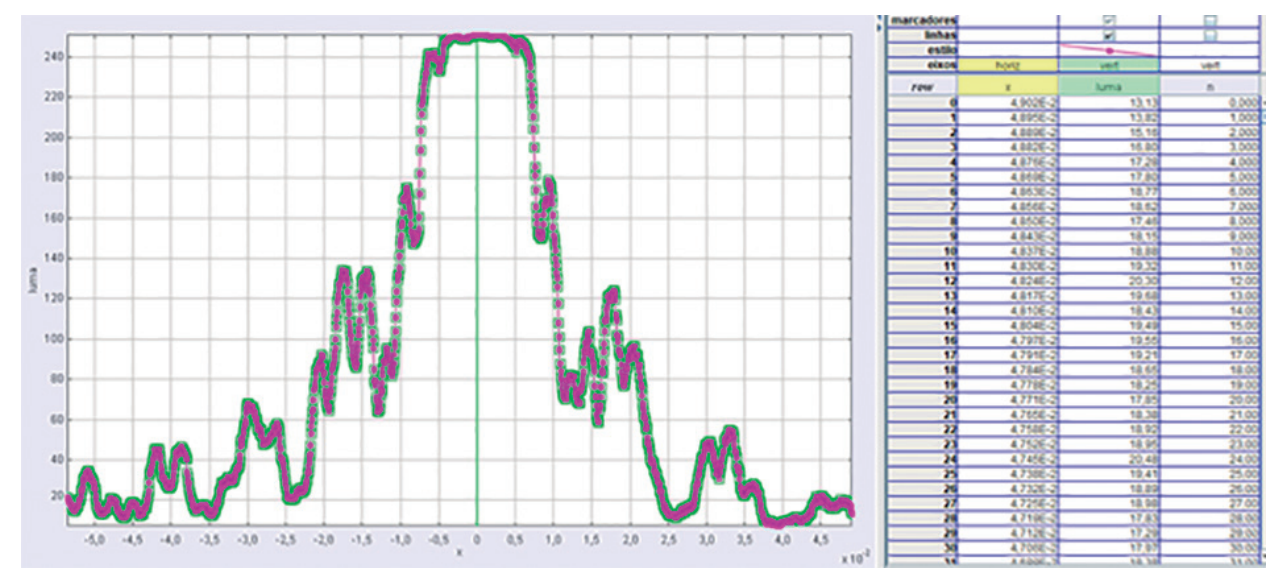

Figura 12: gráfico obtido para a intensidade luminosa em função da distância (fenda dupla)

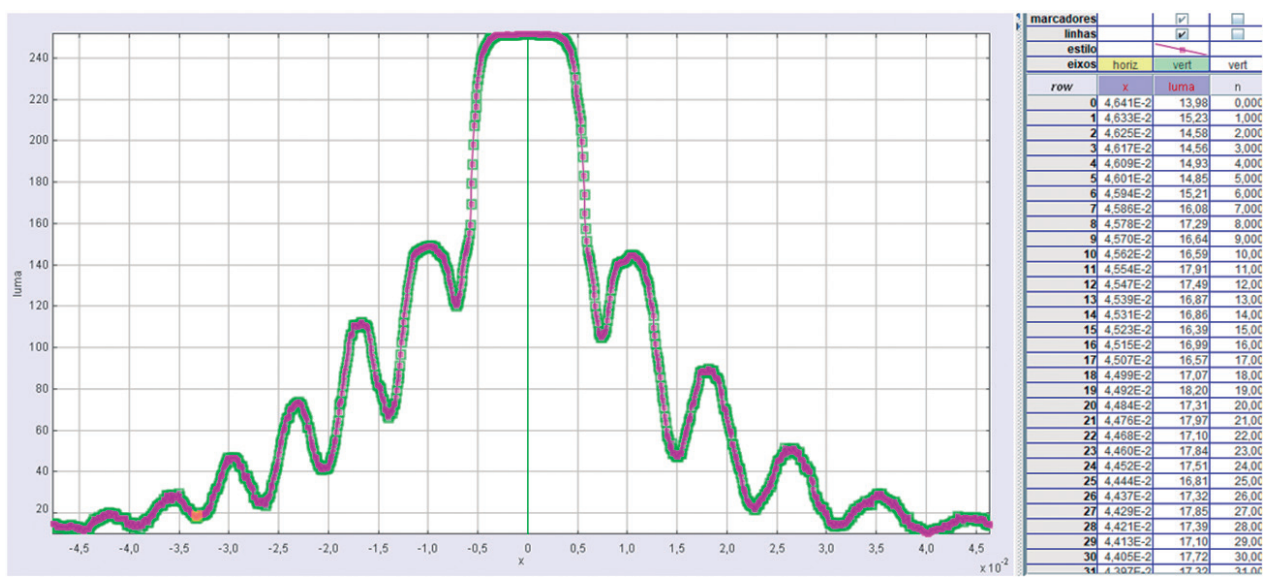

Figura 13: gráfico obtido para a intensidade luminosa em função da distância (fenda única)

É importante perceber com a análise que é possível identificar as franjas de difração e a distância entre cada uma delas (clicando sobre os pontos é permitido saber a posição), o que não seria praticável a olho nu, tendo em vista os valores de distância em milímetros. É válido ressaltar que a simetria do gráfico melhora conforme a qualidade da foto, por exemplo, fotos com a iluminação saturada do laser faz com que os picos fiquem mais irregulares, assim como melhora com a posição bem centralizada do eixo de referência; esse fator pode ser observado pela diferença das figuras 12 e 13. Também deve-se dar uma atenção especial à fotografia, a câmera do celular deve estar num plano paralelo ao plano da imagem, caso contrário, a imagem levemente inclinada faz com que os valores de mínimo/máximo mais afastados do centro apresentem medidas diferentes em relação ao ponto 0 . 
Com o objetivo de deixar especificado para, os valores obtidos para as fendas produzidas nesses trabalhos foram:

$\begin{array}{cc}\text { Abertura da fenda única } & 0,110 \pm 0,005 \mathrm{~mm} \\ \text { Abertura da fenda dupla } & 0,120 \pm 0,005 \mathrm{~mm} \\ \text { Distância entre as fendas da fenda dupla } & 0,310 \pm 0,005 \mathrm{~mm} \\ \text { Comprimento de onda do laser } & 532 \pm 10 \mathrm{~nm} \\ \text { Distância entre o laser e o anteparo } & 1,00 \pm 0,05 \mathrm{~m}\end{array}$

Os valores obtidos acima foram medidos com o auxílio do microscópio utilizado para a montagem das fendas, exceto o comprimento de onda do laser que utilizamos o valor especificado de fábrica.

Com esses dados associados ao comprimento de onda do laser e a distância entre o laser e fenda até o anteparo, é possível desenvolver atividades experimentais quantitativas, além da amostragem qualitativa que é possível fazer com a difração da imagem.

A amostragem qualitativa pode ser feita com a explicação teórica da interferência que a luz sofre e a imagem de difração obtida em cada uma das fendas, observando o que acontece em cada um dos casos e com diferentes distâncias, já um exemplo de atividade quantitativa que pode ser desenvolvida é a utilização da equação (1):

$$
\lambda=\text { n.d.sin } \theta(1)
$$

Assim, é possível que o aluno tente encontrar um valor aproximado para o comprimento de onda do laser utilizando os dados que possui, ou utilizar os outros valores para obter o " $d$ " da fenda produzida.

\section{Considerações finais}

Os resultados obtidos neste trabalho permitem dizer que a construção do aparato experimental apresentou dados consistentes e aproveitáveis para observarmos a teoria de maneira prática.

A montagem do experimento pode ser feita pelos próprios alunos e tem liberdade de alteração das peças, permitindo a fluidez da criatividade e a percepção de que a ciência não é distante e não precisa ser feita com materiais de alto custo. Outro fator de importância é a relevância que pode ser dada ao aluno na participação e criação da aula, permitindo até mesmo o ensino por investigação, o aluno como mediador de seu conhecimento faz com que o ensino se dê de modo facilitado (FREIRE, 1996).

O objetivo final deste trabalho é facilitar que a ciência chegue cada vez mais às escolas e aos alunos, fazendo uso de materiais de baixo custo e de fácil acesso. 


\section{Referências}

Araújo, M; Abib, M. (2003) Atividades experimentais no ensino de física: diferentes enfoques, diferentes finalidades. Revista brasileira de ensino de física, 25(2), 176-194.

Darroz, LM; Rosa, Cleci Terezinha Werner da; Rosa, A B (2016). Experimentos simples para visualização dos fenômenos de difração e interferência da luz. Revista Thema, 13(2), 18-26.

Freire, $\mathrm{P}$ (1996). Pedagogia da autonomia: saberes necessários à prática educativa. São paulo: Paz e Terra.

Inep. Censo escolar. (2018). Recuperado de: http://download.inep.gov. br/educacao_basica/censo_escolar/notas_estatisticas/2018/notas estatisticas_censo_escolar_2018.pdf.

Souza, L.A.; Silva, 1. Da; Huguenin, J.A.O. Balthazar, W.F. (2015). Discutindo a natureza ondulatória da luz e o modelo da óptica geométrica através de uma atividade experimental de baixo custo. Revista brasileira de ensino de física, 37(4), 4311-4316

Tipler, P A; Mosca, G (2006). Física para cientistas e engenheiros - eletricidade e magnetismo, óptica. 6.ed. LTC,

Tracker.Video analysis and modeling tool.versão 5.0.5. Open source physics. Recuperado de http://physlets.org/tracker, 